\title{
Malnutrition Markers and Serum Ghrelin Levels in Hemodialysis Patients
}

\author{
Ezzat Kamel Amin ${ }^{1}$, Azza Ibrahim Eldesouky ${ }^{1}$, Hala Abdel-Hameed Abdel- Aziz², \\ Ola Abdel Rahman Rageb 3 \\ 1- Department of Pediatrics Faculty of Medicine, Zagazig University \\ 2- Clinical pathology department zagazig university \\ 3- Ministry of health
}

\section{Abstract}

\section{Introduction}

Malnutrition is the major co-morbid condition of patients on dialysis, regular monitoring of nutritional status should be apart of treatment .Ghrelin is a stomach-derived hormone

\begin{abstract}
Aim of the Study
The aim of this study is to investigate the changes in levels of serum ghrelin in end-stage renal disease patients receiving dialysis treatment and its relationship to some malnutrition markers.
\end{abstract}

\section{Patients and Methods}

This prospective case control study was conducted in the Nephrology Unit of our University Hospital, 46 patient were included in this study ; they were classified into two groups, cases group comprised 23 children with chronic renal failure on regular hemodialysis control group comprised 23 children matched for age and sex body mass idex, Malnutrition inflammation score, total protein, albumin, blood urea nitrogen, creatinine, total iron binding capacity, ferritin, and cholesterol., Serum ghrelin levels

\section{Results}

Ghrelin was significantly higher in cases than control mean 4769.0957 , Ghrelin sensitivity was $87.0 \%$, specificity was $78.3 \%$, positive predictive value was $80.0 \%$, negative predictive value was $85.7 \%$ and accuracy was $82.6 \%$, cutoff value was $>2070$. Cases showed significant higher than control mean levels for ferritin, cholesterol and lower Hemoglobin, total iron binding capacity and total proteins. Cases showed significant high level of Ghrelin compared to normal control.

\section{Conclusion}

Ghrelin level increased in Hemodialysis patient, increased Ghrelin level might be related to anorexia .It could be used as a prognostic nutritional marker.

\section{Keywords}

Gherlin, malnutrition inflammation score ,Hemodialysis

\section{Running Title}

Malnutrition Marker

\section{Correspondence}

\section{Ezzat Kamel Amin}

Faculty of Medicine, Zagazig University, Sheigk Abu Hamad st. AbuHamad City, Sharqia Governorate, Egypt.

Email:dr_ezat_kamel@yahoo.com Mobile : 01280348470

\author{
geget: The Journal of the Egyptian Society of Pediatric Nephrology and Transplantation (ESPNT) \\ geget https://geget.journals.ekb.eg/ \\ Published by ESPNT http://espnt.net/ \\ Cohosted by Egyptian Knowledge Bank https://www.ekb.eg
}




\section{Introduction}

Malnutrition is the major co-morbid condition of patients on dialysis, regular monitoring of nutritional status should be a part of treatment. [1] Ghrelin is a stomach-derived hormone that acts at the ghrelin receptor in multiple tissues throughout the body. Ghrelin functions through increasing appetite, decreasing system inflammation, increasing cardiac output and increasing (IGF-1) levels. [2] Patients with chronic kidney disease are at substantial risk for malnutrition, characterized by protein energy wasting and micronutrient deficiency. Studies show a high prevalence rate of malnutrition in both children and adults with chronic kidney disease. A clear understanding of the pathophysiologic mechanisms involved in the development of malnutrition in chronic kidney disease is necessary for developing strategies and interventions that are effective, and capable of restoring normal development [3]. Malnutrition Inflammation Score (MIS) is a scoring system for assessment of malnutrition and inflammation ,MIS has 10 components derived from medical history, physical examination, According to several studies, scoring of malnutrition severity in dialysis patients based on MIS is as the following: MIS < 9: no or mild malnutrition, MIS = 9-18: moderate malnutrition, MIS >18: severe malnutrition [4].It is known that serum ghrelin level is strongly higher during fasting and increases with weight loss [5].

\section{Aim of the Study}

The aim of this study is to investigate the changes in levels of serum ghrelin in end-stage renal disease patients receiving dialysis treatment and its relationship to some malnutrition markers.

\section{Patients and Methods}

This prospective case control study was conducted in the Nephrology Unit of Pediatric Department of our University Hospital. A written consent was obtained from parents of the selected subjects. This study was ethicaly approved from our university

Forty six children were included in this study; they were classified into two groups:. Group A "cases group", This group comprised of 23 patients ( 15 females and 8 males) with chronic renal failure on regular hemodialysis for at least three months and maximum 9 years, their age ranged from2-18years, with a standard citrate containing dialysate bath, using biocompatible HD membrane (Polysulphone, FX-80 series, Fresenius, Germany). Blood flow rates ranged from 180 to $250 \mathrm{ml} / \mathrm{min}$. Group B "control group": This group comprised of 23 children matched for age and sex (16 females and 7 males) attending the Pediatric Outpatient Clinic in our University their ages ranged from 2 to 18 years. They were apparently healthy with clinical examination except for minor complains. They had no history of chronic illness and did not receive any medications.

All HD patients were maintained at their target dry body weight received an adequate dose of dialysis (double pool Kt/V $\geq 1.4$ ) receiving three weekly dialysis for a 3 to 4 -h period every session at Pediatric Nephrology Unit of our University Hospital. Inclusion criteria

*Age from 2:18 years

*Under hemodialysis for at least three months
*Include males and females

Exclusion criteria

*Lipid lowering medication and corticosteroids

*Hospitalization during the previous three months

*Infectious, inflammatory diseases, diabetes mellitus, cardiovascular (CVD) and liver disease, thyroid, and cancer Methods

All studied HD children were subjected to the following:

1- Complete history taking as regarding: age and sex, duration of dialysis

2- Clinical examination:

Dry body weight after dialysis and height were measured. , Blood pressure systolic and diastolic was measured before hemodialysis. Body mass index (BMI) weight per kg/height in square meter as one of the markers of nutritional status was evaluated. And Malnutrition inflammation score (MIS): which is a scoring system for assessment of malnutrition and inflammation. MIS has 10 components derived from medical history, physical examination, BMI and laboratory parameters. Each score component is classified according to four levels of severity, from 0 (normal) to 3 (severely abnormal). The sum of all 10 MIS components ranges from 0 (normal) to 30 (severe degree of malnutrition and inflammation status).

3- Laboratory investigation:

*Sample collection: After an overnight fasting, $7 \mathrm{ml}$ of blood samples were collected from all healthy controls and patients immediately before HD.

*Biochemical parameters including total protein, albumin, blood urea nitrogen, creatinine, and iron, total iron binding capacity, ferritin, and total cholesterol concentrations were determined *Serum ghrelin levels were assessed using commercial ELISA kit (Human Ghrelin ELISA). After sample collection, the serum samples were immediately frozen at $-70^{\circ} \mathrm{C}$ until analysis (Mail:shanghai@srbooo.com).

\section{Statistical analysis}

Data collected throughout history, basic clinical examination, laboratory investigations and outcome measures coded, entered and analyzed using Microsoft Excel software. Data were then imported into Statistical Package for the Social Sciences (SPSS version 20.0)

\section{Results}

*Malnutrition Markers.

$\mathrm{BMI}$ as one of the markers of nutritional status was significantly lower in hemodialysis patient. Cases showed significant higher than control mean levels for ferritin but showed significant lower than control mean level for TIBC and HB.Cases showed significant higher than control mean level for Cholesterol but showed significant lower than control mean level for Total protein.

*Ghrelin Hormone Level.

Cases showed significant high level of Ghrelin compared to normal control. Ghrelin sensitivity was $87.0 \%$, specificity was $78.3 \%$, positive predictive value was $80.0 \%$, negative predictive value was $85.7 \%$ and accuracy was $82.6 \%$, cutoff value was $>2070$. 
geget (2019) Volume 14 - Issue 2

*Correlation between laboratory data, malnutrition markers and ghrelin

Ghrelin showed significantly positive correlation with BUN,

Creatinine, Ferritin, cholesterol and MIS.
Print ISSN : 1687 - 613X - Online ISSN : 2636 - 3666

*Ghrelin showed significant negative correlation with HB and total protein this negative correlation between Ghrelin and nutritional markers suggests that low dietary intake causes increases in ghrelin secretion in dialysis patients.

Table 1 Distribution of MIS score according to duration of dialysis

\begin{tabular}{|c|c|c|}
\hline MIS & Number of patients n=23 & Mean duration of dialysis (months) Range \\
\hline 9 & 1 & 24 \\
\hline 10 & 1 & 48 \\
\hline 11 & 1 & 36 \\
\hline 12 & 2 & 25.5 \\
& & $3-48$ \\
\hline 13 & 6 & 47 \\
& & $24-86.4$ \\
\hline 14 & 2 & 84 \\
& & $60-108$ \\
\hline 15 & 6 & 45 \\
& & $12-96$ \\
\hline 16 & 3 & 30.3 \\
& 1 & $7-72$ \\
\hline
\end{tabular}

MIS = Malnutrition inflammation score

Table 2 BMI comparison between cases and control

\begin{tabular}{|c|c|c|c|c|c|c|c|}
\hline & Group & N & Mean & Range & Std. Deviation & T & P \\
\hline $\begin{array}{c}\text { BMI }: \text { Wt } \\
\text { kg / ht m2 }\end{array}$ & Cases & 23 & 16.4522 & $10-23$ & 3.68324 & -2.759 & $0.008^{*}$ \\
\cline { 2 - 6 } & Control & 23 & 19.5652 & $13-28$ & 3.96377 & & \\
\hline
\end{tabular}

Table 3 Lab parameters comparison between cases and control

\begin{tabular}{|c|c|c|c|c|c|c|}
\hline & Group & $\mathbf{N}$ & Mean Range & \pm Std. Deviation & $\mathbf{T}$ & $\mathbf{P}$ \\
\hline \multirow{2}{*}{$\begin{array}{l}\text { Albumin } \\
\text { g/dl }\end{array}$} & Cases & 23 & $3.98913 .6-4.6$ & 0.26553 & \multirow{2}{*}{0.989} & \multirow{2}{*}{0.328} \\
\hline & Control & 23 & $3.9087 \quad 3.5-4.3$ & 0.28590 & & \\
\hline \multirow{2}{*}{$\begin{array}{l}\text { BUN } \\
\mathrm{mg} / \mathrm{dl}\end{array}$} & Cases & 23 & $\begin{array}{l}\text { 49. } 3043 \\
58.4-132.2\end{array}$ & 11.03216 & \multirow{2}{*}{18.530} & \multirow{2}{*}{$0.00 * *$} \\
\hline & Control & 23 & $\begin{array}{c}6.6000 \\
12-16 \\
\end{array}$ & 0.66946 & & \\
\hline \multirow{2}{*}{$\begin{array}{c}\text { Creatinine } \\
\text { mg/dl }\end{array}$} & Cases & 23 & $\begin{array}{c}6.9496 \\
1.45-11.26\end{array}$ & 2.61957 & \multirow{2}{*}{11.043} & \multirow{2}{*}{$0.00 * *$} \\
\hline & Control & 23 & $\begin{array}{l}0.9043 \\
0.7-1.2\end{array}$ & 0.17446 & & \\
\hline \multirow{2}{*}{$\begin{array}{c}\text { Cholesterol } \\
\mathrm{mg} / \mathrm{dl}\end{array}$} & Cases & 23 & $\begin{array}{c}184.4783 \\
155-225\end{array}$ & 19.44659 & \multirow{2}{*}{17.964} & \multirow{2}{*}{$0.00 * *$} \\
\hline & Control & 23 & $\begin{array}{c}81.7391 \\
56-122 \\
\end{array}$ & 19.34194 & & \\
\hline \multirow{2}{*}{$\begin{array}{c}\text { Total Protein } \\
\text { g/dl }\end{array}$} & Cases & 23 & $\begin{array}{l}5.9348 \\
5.4-6.5\end{array}$ & 0.30985 & \multirow{2}{*}{-7.382} & \multirow{2}{*}{$0.00 * *$} \\
\hline & Control & 23 & $\begin{array}{l}7.0652 \\
6.3 .-8.2\end{array}$ & 0.66579 & & \\
\hline
\end{tabular}

Cases were significantly higher as regard, Creatinine, Cholesterol and BUN and significantly lower as regard Total protein with no significant as regard albumin. 
Table 4 Comparison of Iron profile and HB between cases and controls

\begin{tabular}{|c|c|c|c|c|c|c|c|c|}
\hline & Group & $\mathbf{N}$ & Mean & Std. Deviation & Median & Range & $\begin{array}{l}\text { t/ Mann } \\
\text { Whitney }\end{array}$ & $\mathbf{P}$ \\
\hline \multirow{2}{*}{$\begin{array}{c}\text { Iron } \\
\text { mcg/dL }\end{array}$} & Cases & 23 & 82.6000 & 30.05161 & 90 & $25.6-200.5$ & \multirow{2}{*}{0.916} & \multirow{2}{*}{0.365} \\
\hline & Control & 23 & 74.6087 & 12.12338 & 72 & $60-99$ & & \\
\hline \multirow{2}{*}{$\begin{array}{c}\text { Ferritin } \\
\text { ng/Ml }\end{array}$} & Cases & 23 & 1093.808 & 403.5231 & 1016 & $350-3248$ & \multirow{2}{*}{8.364} & \multirow{2}{*}{$0.00 * *$} \\
\hline & Control & 23 & 40.7391 & 17.81526 & 37 & $15-75$ & & \\
\hline \multirow{2}{*}{$\begin{array}{c}\text { TIBC } \\
\mathrm{mcg} / \mathrm{dL}\end{array}$} & Cases & 23 & 211.8391 & 40.76387 & 205.7 & $160.3-343.5$ & \multirow{2}{*}{-6.624} & \multirow{2}{*}{$0.00 * *$} \\
\hline & Control & 23 & 296.9130 & 49.68711 & 278 & $250-405$ & & \\
\hline \multirow{2}{*}{$\begin{array}{l}\text { HB } \\
\text { g/dl }\end{array}$} & Cases & 23 & 9.2174 & 0.87264 & 9 & $7.5-10.8$ & \multirow{2}{*}{-12.615} & \multirow{2}{*}{$0.00 * *$} \\
\hline & Control & 23 & 12.1043 & 0.66570 & 12 & $10.9-13.2$ & & \\
\hline
\end{tabular}

Cases were significantly higher as regard Ferritin and significantly lower as regard TIBC and HB.

Table 5 Ghrelin level comparison between cases and controls

\begin{tabular}{|c|c|c|c|c|c|c|c|}
\hline & Group & $\mathrm{N}$ & Mean Range & Std. Deviation & Median & Mann Whitney & $\mathrm{P}$ \\
\hline \multirow{2}{*}{$\begin{array}{c}\text { Ghrelin } \\
\text { Pg/ml }\end{array}$} & Case & 23 & $4769.0957420-10500$ & 2224.43931 & 5000 & \multirow{2}{*}{3.857} & \multirow{2}{*}{$0.00 * *$} \\
\cline { 2 - 7 } & Control & 23 & $1997.5217230-10000$ & 1522.34574 & 1500 & & \\
\hline
\end{tabular}

Cases showed significant higher level of Ghrelin than normal control

Table 6 Correlation between clinical data and ghrelin

\begin{tabular}{|c|c|c|}
\hline \multicolumn{2}{|c|}{$\mathbf{N = 4 6}$} & \multicolumn{2}{c|}{ Ghrelin } \\
\hline \multirow{2}{*}{ Age } & $\mathrm{R}$ & .290 \\
\cline { 2 - 3 } Weight & $\mathrm{P}$ & .050 \\
\hline \multirow{2}{*}{ Height } & $\mathrm{R}$ & .019 \\
\hline \multirow{2}{*}{ BMI } & $\mathrm{P}$ & .899 \\
\hline & $\mathrm{R}$ & .254 \\
\hline & $\mathrm{P}$ & $-265-$ \\
\hline \multirow{2}{*}{ Duration of dialysis $\mathbf{n}=\mathbf{2 3}$} & $\mathrm{R}$ & .075 \\
\hline & $\mathrm{P}$ & $-047-$ \\
\hline
\end{tabular}

There was no correlation between ghrelin and age, weight, height BMI and duration of dialysis 
Table 7 Correlation between laboratory data and ghrelin $(n=46)$

\begin{tabular}{|c|c|c|}
\hline \multirow{2}{*}{ Albumin } & $\mathbf{R}$ & - 034- \\
\hline & $\mathrm{P}$ & .821 \\
\hline \multirow{2}{*}{ BUN } & $\mathrm{R}$ & $472 * *$ \\
\hline & $\mathrm{P}$ & .001 \\
\hline \multirow{2}{*}{ Creatinine } & $\mathrm{R}$ & $.348 *$ \\
\hline & $\mathrm{P}$ & .018 \\
\hline \multirow{2}{*}{ IRON } & $\mathrm{R}$ & .174 \\
\hline & $\mathrm{P}$ & .246 \\
\hline \multirow{2}{*}{ FERRTIN } & $\mathrm{R}$ & $.373 *$ \\
\hline & $\mathrm{P}$ & .011 \\
\hline \multirow{2}{*}{ TIBC } & $\mathrm{R}$ & $-.180-$ \\
\hline & $\mathrm{P}$ & .231 \\
\hline \multirow{2}{*}{ HB } & $\mathrm{R}$ & $-.518-* *$ \\
\hline & $\mathrm{P}$ & .000 \\
\hline \multirow{2}{*}{ Cholesterol } & $\mathrm{R}$ & $528 * *$ \\
\hline & $\mathrm{P}$ & .000 \\
\hline \multirow{2}{*}{ TOTAL_PROTEIN } & $\mathrm{R}$ & $-.330-*$ \\
\hline & $\mathrm{P}$ & .025 \\
\hline \multirow{2}{*}{ MIS } & $\mathrm{R}$ & $535^{* *}$ \\
\hline & $\mathrm{P}$ & .000 \\
\hline
\end{tabular}

Ghrelin showed significant positive correlation with BUN, Creatinine, Ferritin, cholesterol and MIS and significantly negative correlated with HB and total protein.

Table 8 Validity

\begin{tabular}{|c|c|c|c|c|c|c|}
\hline & Cutoff & Sensitivity & Specificity & +VE predictive & -VE predictive & Accuracy \\
\hline Ghrelin pg/ml & $>2070$ & $87.0 \%$ & $78.3 \%$ & $80.0 \%$ & $85.7 \%$ & $82.6 \%$ \\
\hline
\end{tabular}

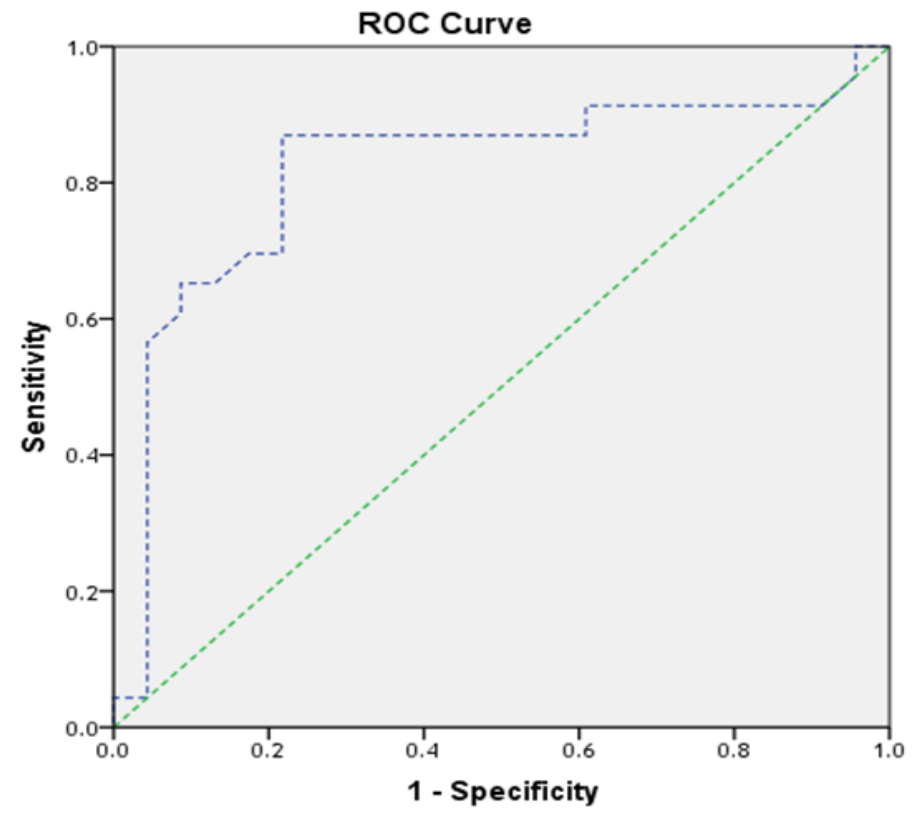

Diagonal segments are produced by ties.

Figure 1 ROC Curve for detection of Ghrelin cut off level of cases 


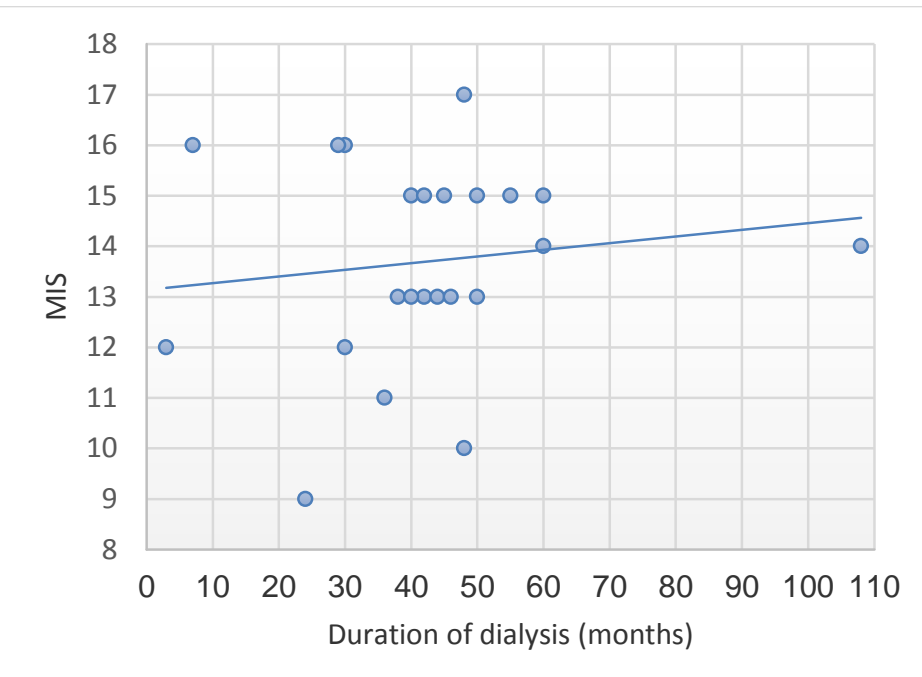

Figure 2 Correlation curve between MIS and mean duration of dialysis

There is no significant correlation between MIS and mean duration of dialysis.

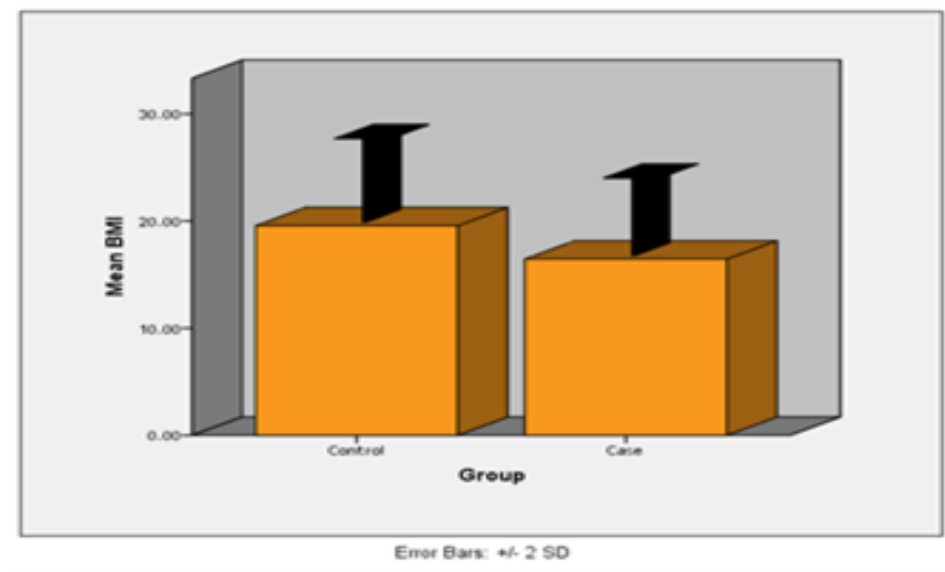

Figure 3 Cases showed significant lower BMI than control

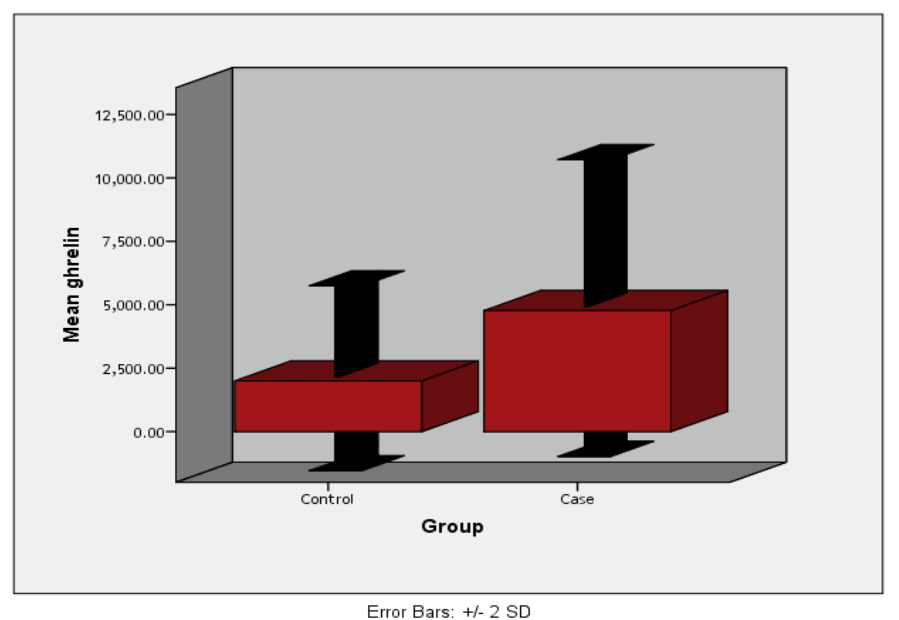

Figure 4 Mean Ghrelin in cases and controls 


\section{Discussion}

Malnutrition is a common problem in patients with end stage renal disease (ESRD) undergoing hemodialysis that may occur secondary to several factors such as inadequate nutritional intake, increased losses, or to an increase in protein catabolism. The results of malnutrition are various and include increased susceptibility to infection, impaired wound healing, poor rehabilitation, fatigue, malaise, and increased rates of hospitalization, morbidity and mortality [6].

Ghrelin, one of the most potent orexigenic hormones, anorexia stimulate Ghrelin secretion to improve appetite to build up fat percentage that is depleted in those malnourished children. This 28-amino acid hormone is produced largely in the stomach. Ghrelin is known to have multiple concurrent actions, including the anti-inflammatory effects, release of growth hormone, fat accumulation, increased food intake, and stimulation of hypothalamic appetite centers, thus it may help to regain appetite and struggle with malnutrition [7].

The aim of the study was to investigate the levels of serum ghrelin in HD patients and its relationship to some malnutrition markers compared with healthy controls. In this study we found that serum ghrelin levels increased in hemodialysis children in comparison to healthy controls. In agreement with our finding Mafra et al., [5] who examined forty-seven HD patients from a single dialysis unit (18 women, mean age $55.3 \pm 12.2 \mathrm{yr}$; BMI $24.4 \pm 4.2 \mathrm{~kg} / \mathrm{m} 2 ; \%$ body fat $29.4 \pm 7.4 \%$ ) were studied and compared to 21 healthy subjects ( 12 women, $50.7 \pm 15.7$ year and BMI $25.6 \pm 4.0 \mathrm{~kg} / \mathrm{m} 2 ; \%$ body fat $30.0 \pm 5.7 \%$ ). Patients showed elevated plasma ghrelin levels when compared to healthy subjects $(1.14 \pm 1.0 \mathrm{ng} / \mathrm{mL}$ vs $0.58 \pm 0.4 ; \mathrm{p}<0.001)$.

In contrast a study made by Amanda et al., [8] who investigated Thirty-six patients $(61.1 \%$ men, $46.7 \pm 14.9$ years, BMI $22.9 \pm 3.9 \mathrm{~kg} / \mathrm{m} 2)$ in regular HD program $(65.0 \pm 46.8$ months). Plasma levels of acyl-ghrelin and inflammatory markers TNF- $\alpha$, IL- 6 and CRP were measured by enzyme immunoassay (ELISA, Enzyme Linked Immunosorbent Assay). Anthropometric parameters were collected for assessment of nutritional status and dietary intake was assessed by food recall. The patients presented elevated plasma levels of IL-6 (83 \pm 10 $\mathrm{pg} / \mathrm{mL}), \mathrm{TNF}-\alpha(21.06 \mathrm{pg} / \mathrm{mL}$ [20.6-40.0]) and CRP (2.7 pg/mL [1.73.4]) compared to normal values. Acylghrelin plasma levels were (18.0 to $77.7 \mathrm{pg} / \mathrm{mL}$ ) $)$ low when compared to healthy individuals. This difference between different studies may be due to difference in age, BMI, duration of HD, duration of ESRF dialysis efficiency or nutritional condition of patients.

Extended research is growing for correlation analysis between P. Ghrelin and chronic malnutrition in CRF .Nutritional and laboratory markers (BMI, MIS, S. albumin, total proteins, cholesterol, HB .iron, TIBC, ferritin) correlation with renal function (blood urea \& creatinine) was extensively studied)

In this study, BMI in patients underlying hemodialysis was markedly reduced compared to controls. This finding was similar to Şahin et al [9] whose study was conducted on malnourished patients undergoing hemodialysis for $46.44 \pm 7.1$ months in Hemodialysis Center, Kayseri, Turkey. Fifteen patients (nine men, six women) undergoing hemodialysis and a control group consisting of 15 healthy volunteers (ten men, five women) were included in that study. The mean age of HD patients was $42.9 \pm 2.11$ years and the mean age of healthy volunteers was $41.0 \pm 2.17$ years ranging from 29 to 60 years. Criteria for inclusion were HD for at least 12 months and three times per week, being malnourished according to the subjective global assessment (SGA), receiving oral diet, without incidental infection, and hemodialysis access via arteriovenous fistula.

We found no significant correlation between serum ghrelin and BMI in hemodialysis patient. Miguel Pérez-Fontán et al., [10] found negative correlation between ghrein and BMI when used a cross-sectional design to study 20 haemodialysis (HD) and 21 peritoneal dialysis (PD) patients, and compared their plasma ghrelin (PGhr) levels with that of an age-matched control group. They also explored correlations between ghrelin and selected hormonal, renal adequacy, nutritional and inflammation markers in both groups.

In this study we found no significant correlation between MIS and duration of dialysis. In agreement with our finding Afshar et al. [11] who found no significant correlation between MIS and duration of dialysis and dialysis efficiency. In contrast to our finding Kalanter-Zadeh et al [12] who found significant correlation between MIS and duration of dialysis. This difference between studies due to difference in duration of dialysis and dialysis efficiency in these studies.

In this study we found no significant difference as regards serum albumin level between cases and controls. Farzaneh Montazerifar et al., [13] found that serum albumin level decreased in cases more than controls. In agreement with our study. Arbeiter et al., [14] made a study on 102 patients with a mean age of 10.3 years (0-18 years) , 24 patients with CRF, 19 children undergoing dialysis treatment (hemodialysis $n=8$, peritoneal dialysis $n=11$ ) and 59 children following renal transplantation. Ten healthy children with a mean age of 7.9 years (1-15 years) served as controls, serum ghrelin and some nutritional markers were investigated in both groups. They found no difference as regards serum albumin level between cases and controls.

Low serum albumin, one of the important nutritional predictors, is associated with mortality and morbidity in renal failure patients [9]. In this study we found positive correlation between serum ghrelin and BUN and creatinine but Farzaneh Montazerifar et al., [13] found a negative correlation observed between serum ghrelin and albumin levels with BUN and creatinine, suggesting that high level of uremic toxin metabolites may lead to decreased serum ghrelin level or impair ghrelin's function which causes anorexia and malnutrition in these patients.

In this study we found that serum cholesterol increased in cases in comparison to controls. Sahin et al., [9] found that serum Cholesterol decreased in cases in comparison to controls. In this study we found that serum ferritin increased and mean TIBC decreased in cases in comparison to controls. These findings is contrast to Sahin et al., [9] who found no significant difference between cases and controls as regard Fe. conc, TIBC and ferritin.

We found also positive correlations between serum ghrelin and MIS in contrast to Sahin et al., [9]. We found positive correlation between total plasma ghrelin and creatinine in renal failure but Yoshimoto et al [15] found no correlation between acylated ghrelin and creatinine. Plasma ghrelin levels elevated in renal failure due to a reduction of ghrelin degradation/clearance in end-stage renal disease. However an overproduction of ghrelin in certain tissues might contribute to its higher plasma concentrations Timo et al., [16]. Jarkovska et 
al., [17] examined 16 patients with ESRD receiving hemodialysis ( 8 men and 8 women) and 19 control healthy subjects (10 men and 9 women). Both groups were comparable in age and BMI, in all subjects they assessed levels of ghrelin, leptin, soluble leptin receptor. They found that total plasma ghrelin did not correlate with creatinine.

Nutritional status estimation found that majority of the patients was mild to moderately malnourished. Malnutrition proves to be an important complication in chronic renal failure. - MIS a reliable method of assessing nutritional status in hemodialysis patients and useful in recommending nutritional support in these patients. However more comparative and longitudinal studies are needed to confirm the validity of this nutrition scoring system.

\section{Limitations of the Study}

The limitations of our study were small sample size, lack of longitudinal data, and we did not measured the levels of protein catabolic rate (PCR), metabolic acidosis, bicarbonate, and chloride, which may also affect appetite and possibly the level of ghrelin in HD patients.

\section{Conclusion}

Ghrelin level increased in Hemodialysis patient, increased Ghrelin level might be related to anorexia .It could be used as a prognostic nutritional marker it is positively correlated with MIS and negatively correlated with $\mathrm{HB}$ and total protein , anorexia with clinical \& lab markers of chronic malnutrition is a constant finding in CRF and contribute to rise of $p$ Ghrelin Elevated s .creatinine and urea toxins contribute to such changes and explain the block in Ghrelin function in improving appetite of these children

Proposed application: the use of changes in plasma Ghrelin as a prognostic marker for nutritional assessment in these patients rather than of any therapeutic value.

\section{References}

1. Wi JW, and Kim NH, Assessment of malnutrition of dialysis patients and comparison of nutritional parameters of CAPD and hemodialysis Patients. Biomed Sci Letters. 2017; 23:185-193.

2. Suzuki H, Asakawa A, Amitani H, NaKamura N,Inui A. Ghrelin and cachexia in chronic kidney disease;in Pediatr Nephrol. 2013: 2013 Apr; 28(4):521-6.

3. Iorember FM, Bamgbola OF. Pilot validation of objective malnutrition-inflammation scores in pediatric and adolescent cohort on chronic maintenance dialysis. SAGE Open Med. 2014, DOI: $10.1177 / 2050312114555564$.

4. Amparo FC, Kamimura MA, Molnar MZ, Cuppari L, Lindholm B, Amodeo C, Carrero JJ, Cordeiro AC. Diagnostic validation and prognostic significance of the malnutrition-inflammation score in nondialyzed chronic kidney disease; in Nephro dialysis transplant. 2015:,30 (5):821-828.

5. Mafra D, Farage NA, Lobo JC, Stockler-Pinto MB, Leal VO, Carvalho DP, Leite M Jr.:Relationship between total ghrelin and inflammation in hemodialysis patients; in Peptides. 2011; 32 (2): 358-361.

6. Kadiri ME, Nechba RB, and Oualim Z, Factors predicting malnutrition in hemodialysis patients; Saudi J Kidney Dis Transpl. 2011; 22 (4):695-704.

7. Colldén G, Tschöp MH, and Müller TD. Therapeutic potential of targeting the ghrelin pathway; International Journal of secret agogue receptor 1a. 2017; 18(4):798.

8. Amanda de Faria BarrosI; Cristiane MoraesI; Milena Barcza Stockler PintoII; Julie Calixto LoboI; Denise MafraI. J. Bras. Nefrol. 2013; vol.35 no.2 São Paulo.

9. Şahin H, Uyanik F, İnanç N, Erdem O. Serum zinc, plasma ghrelin, leptin, selected biochemical parameters and nutritional status in malnourished hemodialysis Patients. Biol Trace Elrm Res. 2009; 127 (3):191-199.

10. Miguel Pérez-Fontán, Fernando Cordido, Ana Rodríguez-Carmona, Javier Peteiro, Rafael GarcíaNaveiro, Jesús García-Buela Plasma ghrelin levels in patients undergoing haemodialysis and peritoneal dialysis. Nephrology Dialysis Transplantation. 2004; 19, 8, 2095-2100.

11. 11-Afshar R, Sanavi S \& Izadi-khah A, Assessment of nutritional status in patients undergoing maintaince hemodialysis: A single-center study from Iran in Saudi J Kidney Dis Transpl. 2007; 18: 397- 404.

12. Kalantar-Zadeh K1, Kopple JD, Block G, Humphreys MH. A malnutration inflammation score is correlated with morbidity and mortility in maintains hemodialysis patients; in American Journal of Kidney disease. 2001:38, 6:1251-63.

13. Farzaneh Montazerifar, Mansour Karajibani, Farnia Gorgij, and Ommolbanin Akbari Malnutrition Markers and Serum Ghrelin Levels in Hemodialysis Patients. International Scholarly Research Notices Volume 2014, Article ID 765895, 5 pages.

14. Arbeiter AK, Büscher R, Petersenn S, Hauffa BP, Mann K, Hoyer PF. Ghrelin and other appetiteregulating hormones in pediatric patients with chronic renal failure during dialysis and following kidney transplantation. Nephrol Dial Transplant. 2008; 24 (2):643-646

15. Yoshimoto A, Mori K, Sugawara A Mukoyama M, Yahata K, Suganami T, Takaya K, Hosoda H, Kojima M, Kangawa K, Nakao K Plasma ghrelin and desacylghrelin concentrations in renal failure. J Am Soc Nephrol. 2002; 13: 2748-2752.

16. Timo D. Müller, Diego Perez-Tilve, Jenny Tong, Paul T. Pfluger, and Matthias H. Tschöp J. Cachexia Sarcopenia Muscle. Ghrelin and its potential in the treatment of eating / wasting disorders and cachexia. J Cachexia Sarcopenia Muscle. 2010; 1(2): 159-167.

17. Jarkovská Z1, Rosická M, Krsek M, Sulková S, Haluzík M, Justová V, Lacinová Z, Marek J . Plasma ghrelin levels in Patients with end-stage renal disease. Physiol Res.2005; 54(4):403-408. 


\section{Statements}

Ethics approval and consent to participate

This study protocol and the consents were approved and deemed sufficient by the Ethical Committee of Zagazig University Hospitals and informed written consent was obtained in every case from their legal guardians

\section{Consent for publication}

"Not applicable

Availability of data and material

"Not applicable

\section{Conflict of interest}

The authors declare no conflict of interest

\section{Funding}

The authors declare that this research work did not revise any fund or funded by authors.

\section{Acknowledgements}

Authors thank patients our collages and soul of Professor.

Doaa Moustafa, Professor of pediatric nephrology. 